\title{
Project Selection Problem by Combination of Shannon Entropy and MCDM Techniques
}

\author{
Azam Keshavarz Haddadha ${ }^{1}$, Ali Namazian ${ }^{2}$, Siamak Haji Yakhchali ${ }^{3}$
}

\begin{abstract}
The Importance of selecting suitable projects among the proposed projects is one of the important decisions and strategies in almost every companies especially the project-based organizations. This paper focuses on developing a model based on Shannon's Entropy and MCDM techniques for solving the project portfolio selection problem, for this purpose, first, the criteria that are suitable for project selection problem, are identified, then, Shannon's Entropy is performed for determining the weights of criteria and fuzzy topsis for ranking projects.
\end{abstract}

Keywords - Project selection; Shannon's Entropy; fuzzy topsis

\section{INTRODUCTION}

$\mathrm{T}$ HE goal of the project selection process is to analyze projects and to approve or reject project proposals based on established criteria, following a set of structured steps. Project selection is the basis of project management system. Selecting the suitable project is always an important task for decision makers.

In recent years, many multi criteria decision making (MCDM) techniques have been developed for dealing with project selection problems. Amiri, employed MCDM methods based on AHP and fuzzy TOPSIS for project selection in oilfield development [1]. Badri et al, used a goal programming model for information system project selection [2]. Carazo et al proposed a comprehensive model for the portfolio of several objectives [3]. Gabriel et al, prepared a multi objective integer optimization model with distributions of costs probability [4]. Ghasemzadeh, et al, applied a 0-1 goal programming for project selection problem [5]. Mahmoodzadeh et al, applied fuzzy AHP and TOPSIS method for project selection problem [10]. Mohanty, used The Technique for Order of Preference by Similarity to Ideal Solution (TOPSIS) approach, as an MCDM technique, for the project selection problem [11]. Mohanty also, proposed a fuzzy analytical network process (ANP) - based approach to project selection [12]. Pangsri,

1: Alaodoleh Semnani Institute of Higher Education, Iran. Email address: azam.keshavaez1369@gmail.com (Azam keshavarz Haddadha).

2: Department of Industrial Engineering, College of Engineering, University of Tehran, Tehran, Iran. Email address: a.namazian@ut.ac.ir (Ali Namazian).

3: Department of Industrial Engineering, College of Engineering, University of Tehran, Tehran, Iran. Email address: yakhchali@yahoo.com (Siamak Haji Yakhchali). applied MCDM techniques in project selection problem, it was based on AHP and TOPSIS methods [13]. There are various methods on project selection in the different fields. Salehi, presented Vikor and AHP methods for project selection problem [16]. Singh proposed a Resource Constrained MultiProject Scheduling with Priority Rules \& Analytic Hierarchy Process for evaluating projects [17]. Also other researches such as ([4], [7], [6], [8], [9], [14], [18] and [19]) used mathematical programming approach for modeling project selection problem.

This paper focuses on introducing a model based on Shannon's Entropy and MCDM techniques (Fuzzy topsis) for solving the project portfolio selection problem. For this purpose, the rest of the paper is organized as follows: Section 2 states the criteria for project selection problem. Sections 3 and 4 discuss Shannon's Entropy and fuzzy topsis techniques to weight criteria. Finally sections 4 and 5 state the results of presented model combined of Shannon entropy and Fuzzy topsis in a numerical example.

\section{Criteria of Project Selection Problem}

In this section, the criteria related to project selection problem are introduced. For criteria identification, some books, thesis, papers and also libraries are reviewed. These criteria are shown in table1.

TABLE1

IDENTIFICATED CRITERIA IN PROJECT PORTFOLIO SELECTION

\begin{tabular}{|c|}
\hline General criteria \\
\hline Project Selection Criteria \\
\hline NPV(Net Present Value) \\
\hline Strategic Plan \\
\hline Projects constraint \\
\hline Competency and Skills of managers and staffs \\
\hline Organizational experience \\
\hline Risks of projects \\
\hline Acquire technology \\
\hline Time delays \\
\hline Competitive advantage \\
\hline Organizations image \\
\hline Stability of rules and performance standards \\
\hline Executive familiar with the project team \\
\hline Staff satisfaction \\
\hline Competences and capabilities of staffing company \\
\hline Marketing plan \\
\hline Customer preferences \\
\hline Human resources \\
\hline
\end{tabular}




\begin{tabular}{|c|}
\hline climate changes \\
\hline $\begin{array}{l}\text { Availability of materials, machinery and other work } \\
\text { essentials }\end{array}$ \\
\hline $\begin{array}{l}\text { Work experience with an employer or other elements of } \\
\text { the project in previous projects }\end{array}$ \\
\hline Costs \\
\hline $\begin{array}{l}\text { Anticipated cash flow interaction of the project with } \\
\text { existing projects }\end{array}$ \\
\hline The availability of time and human resources \\
\hline revenue growth of Company \\
\hline Price Fluctuations \\
\hline The prepayment \\
\hline The size of the organization and the need for new project \\
\hline basic systems for Implementation of the projects \\
\hline IRR(Investment Return Rate) \\
\hline
\end{tabular}

\section{SHANNON'S ENTROPY}

Entropy algorithm is one of the useful tools for acquiring weights of criteria. Consider $\mathrm{Pij}$ in decision matrix for alternatives' evaluation. There are $\mathrm{n}$ alternatives and $\mathrm{K}$ criteria in decision matrix. The probability of each element is distributed based on its probability function. The element of this matrix for jth criterion is as below:

$$
\begin{gathered}
P_{i j}=\frac{f_{j}\left(a_{i}\right)}{\sum_{i=1}^{n} f_{j}\left(a_{i}\right)} \\
E_{j}=-M \sum_{i=1}^{n} P_{i j} \ln P_{i j}
\end{gathered}
$$

$\mathrm{M}$ as a constant is calculated based on the following equation:

$$
M=\frac{1}{\ln (n)}
$$

And $E_{j}$ is a value between 0 and 1 .

Next step is to calculate deviation degree (di) which says that to what extent jth criterion has useful information for decision maker. If there is little difference between one criterion values, it means that alternatives are indifferent according to this criterion so its effect in decision making should be diminished. Deviation degree is obtained as below:

$$
d_{i}=1-E_{i} \quad j
$$

The final step in Shannon entropy is to obtain weights based on following equation:

$$
w_{j}=\frac{d_{j}}{\sum_{j=1}^{k} d_{j}}
$$

\section{FUZZY TOPSIS}

Having calculated the weight of each criterion by using Shannon entropy, the next step is to adopt the fuzzy TOPSIS method as the ranking method for ranking projects.

The fuzzy TOPSIS method consists of following steps (Chen 2000):

Step 1: Construct the fuzzy decision matrix $\widetilde{D}$ for $\mathrm{m}$ criteria and $\mathrm{n}$ alternatives. $\tilde{X}_{i i}=\left(a_{i j}, b_{i j}, c_{i j}\right)$ represents the transformed TFNs from linguistic terms.
$\widetilde{D}$ is represented as follows:

$$
\widetilde{D}=\begin{array}{ccc}
\tilde{X}_{1,} & \cdots & \tilde{X}_{1 n} \\
\vdots & \ddots & \vdots \\
\tilde{X}_{m}, & \cdots & \tilde{X}_{m n}
\end{array}
$$

Step 2: Calculate the normalized fuzzy decision matrix $\tilde{R}$ as follows:

$$
\tilde{R}=\left[\tilde{r}_{i j}\right]_{m * n}
$$

The normalized is calculated as:

$$
\begin{gathered}
\tilde{r}_{i j}=\left[\frac{a_{i j}}{c_{j}^{*}}, \frac{b_{i j}}{c_{j}^{*}}, \frac{c_{i j}}{c_{j}^{*}}\right] \\
c_{j}^{*}=\max c_{i j} \quad i=1, r, \ldots, m \quad j=1, r, \ldots, n
\end{gathered}
$$

To avoid the effect of outliers, TOPSIS needs to normalize the decision matrix.

Step 3: Calculate the weighted normalized decision matrix $\tilde{V}$ : In this study, the weights are obtained from previous ANP approach. The weighted normalized value $\tilde{V}_{i j}$ is calculated as follows:

$$
\begin{gathered}
\tilde{V}_{i j}=w_{i} r_{i j} i=1, r, \ldots, m \quad j=1, r, \ldots, n \\
\tilde{V}=\left[\tilde{V}_{i j}\right]_{\min }
\end{gathered}
$$

Where $W_{i}$ is the weight of the ith criterion and

$$
\sum_{i=1}^{m} W_{i}=1
$$

Step 4: Determine the fuzzy positive ideal solution $A^{*}$ and fuzzy negative ideal solution $A^{-}$.

$$
\begin{gathered}
A^{*}=\left(\tilde{v}_{1}^{*}, \tilde{v}_{r}^{*}, \ldots, \tilde{v}_{n}^{*}\right) \\
A^{-}=\left(\tilde{v}_{i}^{-}, \tilde{v}_{r}^{-}, \ldots, \tilde{v}_{n}^{-}\right) \\
v_{j}^{*}=(1,1,1) \text { and } v_{j}^{-}=(*, \cdot *)
\end{gathered}
$$

Step 5: Calculate the distance of each alternative using $A^{*}$ and $A^{-}$as follows:

Where

$$
\begin{gathered}
D_{j}^{*}=\sum_{i=1}^{m} d\left(\tilde{v}_{i j}, \tilde{v}_{i}^{*}\right) j=1, r, \ldots, n \\
D_{j}^{-}=\sum_{i=1}^{m} d\left(\tilde{v}_{i j}, \tilde{v}_{i}^{-}\right) j=1, r, \ldots, n
\end{gathered}
$$

$$
d(\widetilde{A}, \widetilde{B})=\sqrt{\left.1 / r^{\top}\left[(a)-b^{1}\right)^{r}+\left(a^{r}-b^{r}\right)^{r}+\left(a^{r}-b^{r}\right)^{r}\right]}
$$

Step 6: Calculate the relative closeness to the positive ideal solution: The relative closeness of the alternative $A_{i}$ with respect to $A^{*}$ is defined as: 
$R C_{j}^{*}=\frac{D_{j}^{-}}{D_{j}^{*}+D_{j}^{-}} \quad i=1, r, \ldots, n$

Step 7: Rank the preference order: The index values of $R C_{j}^{*}$ lie between 0 and 1 . The larger index value means closer to a positive ideal solution for alternatives.

\section{THE CRITERIA WeIGHTING}

In the first stage, candidate projects and the criteria are determined.

TABLE III.

IDENTIFIED CRITERIA IN THE PROPOSED MODEL

\begin{tabular}{|c|c|}
\hline $\begin{array}{c}\text { Criterion } \\
\text { Index }\end{array}$ & Criterion \\
\hline C1 & Price Fluctuations \\
\hline C2 & RPV(Net Present Value) \\
\hline C3 & Time delays \\
\hline C4 & Organizational experience \\
\hline C5 & Executive familiar with the project team \\
\hline C6 & $\begin{array}{c}\text { Availability of materials, machinery and } \\
\text { other work essentials }\end{array}$ \\
\hline C7 & Costs \\
\hline C8 & The availability of time and human \\
resources
\end{tabular}

Based on the information from five experts, the following results were obtained:

TABLE IV

\begin{tabular}{|c|c|c|c|c|c|}
\multicolumn{1}{c|}{} & \multicolumn{1}{c}{ EXPERT'S OPINIONS ABOUT CRITERIA } \\
\cline { 2 - 6 } \multicolumn{1}{c|}{} & N1 & N2 & N3 & N4 & N5 \\
\hline C1 & 2 & 3 & 4 & 4 & 3 \\
\hline C2 & 2 & 6 & 5 & 3 & 1 \\
\hline C3 & 3 & 4 & 3 & 2 & 6 \\
\hline C4 & 3 & 7 & 5 & 6 & 4 \\
\hline C5 & 3 & 4 & 2 & 1 & 1 \\
\hline C6 & 2 & 2 & 3 & 3 & 5 \\
\hline C7 & 4 & 5 & 5 & 8 & 5 \\
\hline C8 & 1 & 2 & 3 & 5 & 4 \\
\hline C9 & 3 & 2 & 5 & 4 & 3 \\
\hline C10 & 3 & 4 & 5 & 5 & 1 \\
\hline C11 & 6 & 7 & 5 & 4 & 2 \\
\hline C12 & 2 & 3 & 4 & 5 & 6 \\
\hline C13 & 1 & 4 & 5 & 6 & 3 \\
\hline
\end{tabular}

As a result, regarding to Shannon's Entropy approach, the weights of the criteria are as follow:
TABLE IV

THE RESULTS OF SHANNON'S ENTROPY

\begin{tabular}{|c|c|}
\hline Criterion Index & Weight \\
\hline C1 & 0.027204 \\
\hline C2 & 0.149611 \\
\hline C3 & 0.064262 \\
\hline C4 & 0.038942 \\
\hline C5 & 0.134311 \\
\hline C6 & 0.059078 \\
\hline C7 & 0.027795 \\
\hline C8 & 0.11377 \\
\hline C 9 & 0.042839 \\
\hline C10 & 0.099205 \\
\hline C11 12 & 0.067482 \\
\hline C13 & 0.061746 \\
\hline & 0.113753 \\
\hline
\end{tabular}

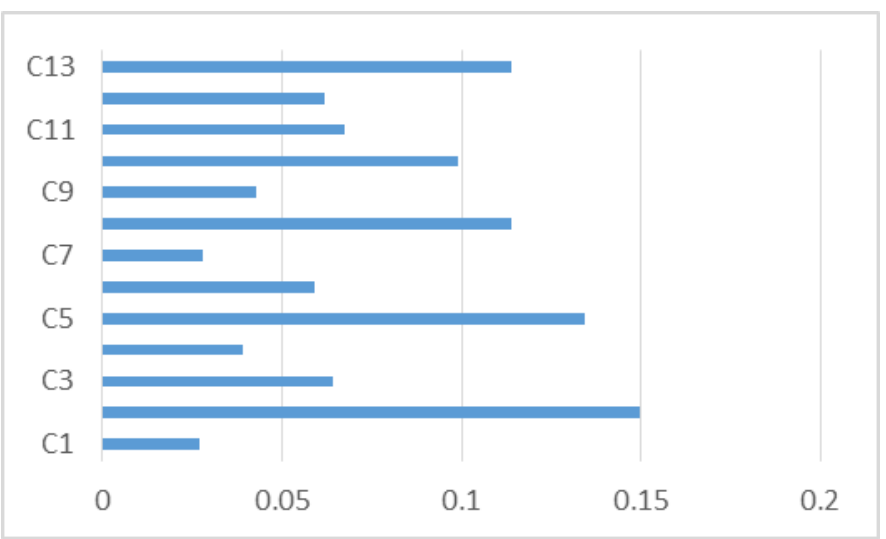

Fig. 1. Criteria weight

After calculating the weights of criteria, at the next step, the weights of projects should be determined. Using topsis technique, these weight are as what shown in table 5.

TABLE V

THE RESULTS OF FUZZY TOPSIS

\begin{tabular}{|c|c|c|c|}
\hline \multirow{2}{*}{ Projects } & $D_{j}^{*}$ & $D_{j}^{-}$ & $R C_{j}^{*}$ \\
\hline P1 & 0.649 & 0.950 & 0.594 \\
\hline P2 & 0.818 & 0.768 & 0.484 \\
\hline P3 & 0.691 & 0.880 & 0.560 \\
\hline
\end{tabular}

Weights of projects show that the results of ranked projects. According to this table, among different projects, P1 is the best choice.

\section{SUMMARY AND CONCLUSION}

One of the basic tasks for decision makers is related to project selection problem. Selection of a suitable project portfolio is an important decision that project-based organizations are encounter with. Selecting the right projects is always a difficult task for decision makers. This study proposes a model for the project selection problem with combination of MCDM and Shannon entropy techniques. For future researches, using combination of other MCDM 
techniques under fuzzy environment for dealing with project selection problem can be suggested.

\section{REFERENCES}

[1] Amiri, M.P, (2010). "Project selection for oil-fields development by using AHP and fuzzy TOPSIS method, Expert systems with applications, 37(9), 6218-66224. https://doi.org/10.1016/j.eswa.2010.02.103

[2] Badri, M. A., Davis, D., \& Davis, D. (2001). A comprehensive 0-1 goal programming model for project selection. International Journal of Project Management, 19(4), 243-252. https://doi.org/10.1016/S0263-7863(99)00078-2

[3] F. Carazo, T. Gómez, J. Molina, A. G. Hernández-Díaz, F. M. Guerrero, and R. Caballero, "Solving a comprehensive model for multiobjective project portfolio selection," Computers \& Operations Research, vol. 37, no. 4, pp. 630-639, Apr. 2010. https://doi.org/10.1016/j.cor.2009.06.012

[4] Gabriel, S. A., Kumar, S., Ordonez, J., \& Nasserian, A. "A multiobjective optimization model for project selection with probabilistic considerations." Socio-Economic Planning Sciences, 40(4), 2006: pp.297-313. https://doi.org/10.1016/j.seps.2005.02.002

[5] Ghasemzadeh, F., Archer, N., \& Iyogun, P. (1999). A zero-one model for project portfolio selection and scheduling. Journal of the Operational Research Society, 50(7), 745-755. https://doi.org/10.1057/palgrave.jors.2600767

[6] Hall, N. G., Hershey, J. C., Kessler, L. G., \& Stotts, R. C. "A model for making project funding decisions at the National Cancer Institute." Operations Research, 40(6),, 1992: pp.1040-1052. https://doi.org/10.1287/opre.40.6.1040

[7] Hawkins, C. A., \& Adams, R. A. "A goal programming model for capital budgeting." Financial Management, 1974: pp.52-57. https://doi.org/10.2307/3665071

[8] Khalili-Damghani, K., Tavana, M., \& Sadi-Nezhad, S. (2012). An integrated multi-objective framework for solving multi-period project selection problems. Applied Mathematics and Computation, 219, 31223138.

https://doi.org/10.1016/j.amc.2012.09.043

[9] Kaveh Khalili-Damghania , Soheil Sadi-Nezhad ," A hybrid fuzzy multiple criteria group decision making approach for sustainable project selection" , Applied Soft Computing 13 (2013) 339-352. https://doi.org/10.1016/j.asoc.2012.07.030

[10] Mahmoodzadeh. S, Shahrabi. J, Parizar. M, Zaeri. M. S, "Project selection by using fuzzy AHP \& TOPSIS technique, World Academy of science, Engineering and Technology: 30.

[11] Mohanty, R. P. "Project selection by a multiple-criteria decision-making method: an example." International Journal of Project Management, 10(1),, 1992: pp.31-38. https://doi.org/10.1016/0263-7863(92)90070-P

[12] Mohanty, R. P., Agarwal, R., Choudhury, A. K., \& Tiwari, M. K. "A fuzzy ANP-based approach to R\&D project selection: a case study." International Journal of Production Research 43(24), 2005: pp.51995216. https://doi.org/10.1080/00207540500219031

[13] Pangsri, P., (2015) .Application of the Multi Criteria Decision Making Methods for Project Selection .Universal Journal of Management 3(1, ( pp. pp.15-20. https://doi.org/10.13189/ujm.2015.030103

[14] Rabbani, M., Aramoon Bajestani, M., \& Baharian Khoshkhou, G. "A multi-objective particle swarm optimization for project selection problem ." Expert Systems with Applications 37(1), 2010: pp.315-321. https://doi.org/10.1016/j.eswa.2009.05.056

[15] Saaty, T.L., "Axiomatic foundations of analytic hierarchy process", Management Science, vol. 32 no.7, 1986. 841-855. https://doi.org/10.1287/mnsc.32.7.841
[16] Salehi, Kayvan ,. "A hybrid fuzzy MCDM approach for project selection problem." Decision Science Letters ,4, 2015: pp.109-116. https://doi.org/10.5267/j.ds1.2014.8.003

[17] Singh, " Resource Constrained Multi-Project Scheduling with Priority Rules \& Analytic Hierarchy Process" , Procedia Engineering, vol 69, pp. 725 - 734.2014.

[18] Weingartner, H. M. "Capital budgeting of interrelated projects: survey and synthesis." Management Science, 12(7), 1996: pp.485-516. https://doi.org/10.1287/mnsc.12.7.485

[19] Yavuz, S., \& Captain, T. A. "Making project selection decisions: a multi-period capital budgeting problem." International Journal of Industrial Engineering, 9(3),, 2002: pp.301-310. 